\title{
The effects of nutrients on mood
}

\author{
David Benton* and Rachael T Donohoe \\ *Department of Psychology, University of Wales Swansea, Swansea SA2 8PP, UK
}

Accepted: 13 May 1999

\begin{abstract}
A recent major theory was that a meal high in carbohydrate increased the rate that tryptophan enters the brain, leading to an increase in the level of the neurotransmitter serotonin that modulates mood. Although such a mechanism may be important under laboratory conditions it is unlikely to be of significance following the eating of any typical meal. As little as $2-4 \%$ of the calories of a meal as protein will prevent an increased availability of tryptophan. Arguably the food with the greatest impact on mood is chocolate. Those who crave chocolate tend to do so when they feel emotionally low. There have been a series of suggestions that chocolate's mood elevating properties reflect 'drug-like' constituents including anandamines, caffeine, phenylethylamine and magnesium. However, the levels of these substances are so low as to preclude such influences. As all palatable foods stimulate endorphin release in the brain this is the most likely mechanism to account for the elevation of mood. A deficiency of many vitamins is associated with psychological symptoms. In some elderly patients folate deficiency is associated with depression. In four double-blind studies an improvement in thiamine status was associated with improved mood. Iron deficiency anaemia is common, particularly in women, and is associated with apathy, depression and rapid fatigue when exercising.
\end{abstract}

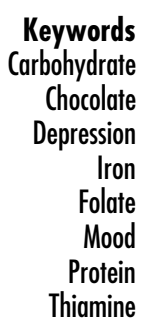

\section{Key messages}

- The intake of carbohydrate is associated with improved mood.

- Poor mood stimulates the eating of 'comfort foods' such as chocolate.

- A deficiency of many micro-nutrients is associated with poorer mood, in particular thiamine and iron.

\section{Introduction}

There have been many suggestions that aspects of both macro- and micro-nutrient intake influence mood. As space precludes a systematic examination of the entire area several of the more important are introduced.

\section{Macro-nutrient intake and depression}

Wurtman and Wurtman ${ }^{1}$ developed the hypothesis that carbohydrates can relieve depression, a suggestion that depended on three disorders; carbohydrate craving obesity, the pre-menstrual syndrome and seasonal affective disorders. They proposed that an increase in carbohydrate intake reflected an attempt at selfmedication, that carbohydrate intake enhanced serotonin synthesis.

The Wurtmans' suggested that in normal individuals an increase in brain serotonin changes our food preferences, we no longer like carbohydrate to the same extent and eat other macro-nutrients. They proposed that some obese people suffer from a disturbance of this feedback mechanism such that after eating carbohydrate the mechanism that should stop further carbohydrate intake fails to work. When those suffering with carbohydrate craving obesity were offered snacks that differed in macro-nutrient composition, towards the late afternoon, they snacked almost entirely on high carbohydrate foods, although they did not eat more at meal times ${ }^{1}$. When asked why they snacked the response was more likely to be that it made them feel more calm or clearheaded, rather than to satisfy hunger. Those who were carbohydrate cravers felt less depressed and more alert. Those who did not crave carbohydrate felt sleepy and fatigued.

Those suffering with Seasonal Affective Disorder (SAD) typically eat more in the winter and put on weight. From the Wurtmans' perspective this is an attempt to decrease depressive symptoms by eating carbohydrate rich foods. The eating of a carbohydraterich/protein-poor meal was associated with improved mood in those suffering with $\mathrm{SAD}^{2}$.

The prediction that a high carbohydrate intake influences only those who are depressed has been questioned. De Castro ${ }^{3}$ asked normal subjects to keep dietary diaries from which he calculated the proportion of calories that came in the form of carbohydrates. Over a nine-day period he found that a higher intake of carbohydrate was associated with feeling less 
depressed and more energetic. A higher intake of protein was also associated with feeling more depressed. An interesting aspect of these data is that the associations were not apparent when particular meals were related to mood around the time of eating. Similarly a positive relationship was reported between the amount of carbohydrate consumed, over a seven-day period, and positive mood in a group of control subjects, although not in bulimic patients ${ }^{4}$.

The correlational nature of these studies makes the data difficult to interpret. It is unclear whether carbohydrate leads to a better mood or whether those who are depressed eat more carbohydrate. However, when subjects ate diets that contained either low, medium or high levels of carbohydrate for one week, the consumption of the low carbohydrate diet was associated with increased anger, depression and tension $^{5}$. The consumption of a low carbohydrate/ high protein breakfast for three weeks resulted in reports of increased anger ${ }^{6}$. A further study, however, found no difference when high and low carbohydrate diets were compared over three days ${ }^{7}$.

The relative consistency of the finding that the consumption of a diet high in carbohydrate is associated with better mood suggests that it is a robust phenomenon. Such findings do, however, conflict with the view that the phenomenon should only be observed in depressed individuals and that mood should be altered in the hours following eating ${ }^{1}$.

\section{The Wurtman hypothesis}

The most quoted hypothesis ${ }^{1}$ concerning diet and mood is that a high carbohydrate meal increases the ratio in the plasma of tryptophan to 'large neutral amino acids' (tyrosine, phenylalanine, leucine, isoleucine and valine). The release of insulin in response to raised levels of blood glucose facilitates the uptake of most amino acids, but not tryptophan, into peripheral tissues such as muscle. In contrast tryptophan is bound to blood albumin and insulin increases the affinity of albumin for tryptophan. The result is that the ratio of tryptophan to the other amino-acids in the blood increases.

Tryptophan and the other large neutral amino acids compete with each other for a transporter molecule that allows entry into the brain. Thus, when a high carbohydrate meal increases the ratio of tryptophan to other large amino acids, relatively more tryptophan is transported into the brain. Tryptophan is the precursor of the neurotransmitter serotonin into which it is transformed by the enzyme tryptophan hydroxylase. Normally tryptophan hydroxylase is not fully saturated and any increased transportation of tryptophan into the brain results in an increase in serotonin synthesis and serotinergic neurotransmission.
As there is relatively little tryptophan in protein, compared to other amino acids, the consumption of a meal high in protein will result in a low ratio of tryptophan to other amino acids. It therefore follows that the rate at which tryptophan enters the brain will be lower ${ }^{8}$. The behavioural consequences of increased serotinergic activity include changes in aggressiveness, mood and pain sensitivity.

A test of the hypothesis that meals differing in protein and carbohydrate content will have different physiological consequences is offered by the measurement of the ratio of tryptophan to long chain neutral amino acids in plasma. A series of studies have found, as predicted, differences in this ratio after high carbohydrate as opposed to high protein meals ${ }^{9-11}$. Similar effects were observed in the obese $^{12}$ and those suffering with Seasonal Affective Disorder $^{2}$. Although superficially supportive of the Wurtman theory, the practical significance of these findings is unclear.

Table 1 summarizes the results of 30 human studies that have looked at the influence of meals that differed in the percentage of calories that came from protein rather than carbohydrate. There is clear support for the theory of Wurtman that the ratio of carbohydrate to protein in a meal influences the ratio between tryptophan and long chain neutral amino acids. However, these data do not give support for anything other than the first step of the theory. Clearly when protein offers less than $2 \%$ of the calories then the ratio of amino acids in plasma markedly favours tryptophan. However, as little as $5 \%$ of the calories in the form of protein is enough to ensure that this does not happen. It is easier to decrease the availability of tryptophan to the bloodbrain transport molecule, by consuming a large amount of protein, than it is to increase it by consuming a large amount of carbohydrate. No normal meal will contain so little protein that the uptake of tryptophan will be increased. Even foods that are said to be high in carbohydrate contain relatively high levels of protein. In potatoes $10 \%$ of the calories come in the form of protein and in bread 15\%. If anything these food items,

Table 1 The influence of protein in a meal on the ratio of tryptophan to long-chain neutral amino acids. Data from thirty studies are summarized. Meals are classified in the first column in terms of the percentage calories that were in the form of protein. The ratio of the tryptophan (T) to long-chain neutral amino acids (LNAA) in the plasma is expressed as a percentage of baseline values

\begin{tabular}{lccc}
\hline $\begin{array}{l}\% \text { Calories } \\
\text { as protein }\end{array}$ & $\begin{array}{c}\text { Number of } \\
\text { subjects }\end{array}$ & $\begin{array}{c}\text { T/LNAA } \\
\text { as \% baseline }\end{array}$ & $\begin{array}{c}\text { Significant } \\
\text { studies }\end{array}$ \\
\hline$<2 \%$ & 140 & $123 \%$ & $10 / 14$ \\
$4 \%$ & 10 & $109 \%$ & $0 / 1$ \\
$5-10 \%$ & 34 & $101 \%$ & $0 / 4$ \\
$12-19 \%$ & 18 & $94 \%$ & $0 / 2$ \\
$20-49 \%$ & 24 & $75 \%$ & $2 / 3$ \\
$>50 \%$ & 67 & $67 \%$ & $4 / 6$ \\
\hline
\end{tabular}


traditionally described as 'high carbohydrate', will decrease the availability of tryptophan for transport into the brain.

There is little support for the suggestion that carbohydrate selectively benefits the depressed, rather it appears to have a general beneficial effect ${ }^{3}$. The mechanism by which an increased carbohydrate intake improves mood remains obscure.

\section{Chocolate and emotional comfort}

When attitudes to chocolate were explored, using factor analysis, two major factors resulted ${ }^{13}$. The first factor was labelled craving and was associated with a considerable preoccupation with chocolate and eating it compulsively. The questions fell into two groups. Chocolate was "overpowering," "preys on my mind," you cannot "take it or leave it" and "can't get it out of my head." The weakness for chocolate occurred when under emotional stress; "when I am bored", "to cheer me up", "when I am upset" and "when I am down." The coupling of these two groups of questions suggested a link between negative mood and an intense desire to consume chocolate.

The second factor also included two types of question. Firstly there are comments associating chocolate with negative experiences: I feel "unattractive," "sick," "guilty," "depressed," "unhealthy" after eating chocolate. It is not surprising that after eating chocolate "I often wish I hadn't." Associated with this guilt are comments related to weight and body shape: "I often diet," "I look at the calorific value of a chocolate snack," "If I ate less chocolate I think I would have a better figure." The second factor was labelled "guilt." Hetherington and MacDiarmid ${ }^{14}$ commented that self-reported 'chocolate addicts' do not represent an homogeneous group. It may well be that some selfreported 'chocolate addicts' feel guilt whilst others do not.

The factor analytical approach confirmed ${ }^{13}$, in a normal population, the impression created previously when those with psychological problems have been considered. Chocolate is consumed in moments of emotional distress, it is consumed for its comforting properties. A group who reported "self-medicating" with chocolate were more likely to have personality traits associated with hysteroid dysphoria, a syndrome characterized by episodes of depression in response to feeling rejected ${ }^{15}$. The experience of strong food cravings was associated with being more bored, anxious and having a dysphoric mood ${ }^{16}$. Although a desire for chocolate was associated with depression it was not found to be related to suicidal thoughts ${ }^{17}$.

A recent study is the only one to systematically vary mood and look at chocolate intake ${ }^{18}$. Music was used to induce either a happy or sad mood. Chocolate intake, but not intake of the chocolate substitute carob, increased in those who heard the sad music.

Benton ${ }^{19}$ discussed the mechanisms that are associated with the ability of chocolate to improve mood. Some have suggested that the mechanism suggested by Wurtman (see above) accounts for chocolates mood elevating properties. In this context chocolate is described as a high carbohydrate containing food with the implication that the passage of tryptophan into the brain is stimulated. However, as chocolate contains $13 \%$ protein it would decrease rather than increase the uptake of tryptophan (Table 1). A variety of 'drug-like' mechanisms were proposed. Chocolate contains anandamides that act at the same site in the brain as cannabis ${ }^{20}$. Phenylethylamine, acts in a similar manner to amphetamine and is also found in chocolate. A $50 \mathrm{~g}$ bar of chocolate will provide in the range of 10 to $30 \mathrm{mg}$ of caffeine, a dose that compares with the $85 \mathrm{mg}$ $/ 150 \mathrm{ml}$ found in coffee. A bar of chocolate will provide from 25 to $50 \mathrm{mg}$ of magnesium and the increased chocolate craving in the pre-menstrual stage has been proposed to be an attempt to increase the intake of this mineral. Benton ${ }^{19}$ considered these suggestions and concluded that the levels of these 'drug-like' substances provided by a bar of chocolate were several orders of magnitude less than those needed to produce a pharmacological action.

A critical experiment compared the ability of brown chocolate, white chocolate and cocoa powder to satisfy chocolate craving ${ }^{21}$. When in their everyday life subjects experienced chocolate craving they opened a box and found either white or brown chocolate, or some of their constituents, that they consumed. They recorded the extent to which their chocolate craving was satisfied. As the putative 'drug-like' constituents of chocolate are found in cocoa powder, if these drugs are critical to the satisfaction of chocolate craving, chocolate craving should be satisfied by cocoa powder. It was not. The conclusion was that the critical factor that satisfied chocolate craving was the taste and mouth-feel.

Benton ${ }^{19}$ concluded that the most likely basis of the attraction of chocolate is that it stimulates the release of endorphins. The intake of sweet items and other palatable foods is increased by opiate agonists and decreased by antagonists ${ }^{22,23}$. There is considerable evidence that in rats endogenous opiates regulate food intake by modulating the extent to which pleasure is induced by palatable foods. In humans opioid antagonists decrease thinking about food ${ }^{24,25}$ and food intake ${ }^{26,27}$. It was proposed that with a monotonous diet the endogenous opiate system does not control eating. However, under stress, or when consuming highly palatable foods, it plays a role 28 .

Thus in both normal subjects, and those chosen because of their psychiatric complaints, there is an 
association between chocolate craving and its consumption when emotionally stressed.

\section{Micro-nutrient status and mood}

With vitamin deficiency psychological symptoms such as depression, hysteria and hypochondria may appear earlier than the symptoms of an out-right deficiency disease; this was observed when low levels of thiamine ${ }^{29}$, riboflavin ${ }^{30}$, vitamin $\mathrm{C}$, but not vitamin $\mathrm{A}^{31}$, have been experimentally induced. Numerous investigators have reported associations between deficiencies of folate or vitamin $\mathrm{B}_{12}$ and psychiatric syndromes including depression and dementia ${ }^{32-38}$. Some workers have hypothesized that in the elderly cognitive impairment and organic psychosis are often associated with $\mathrm{B}_{12}$ deficiency $^{36}$, whereas depression is associated with folate deficiency ${ }^{34,38}$. However, it should be remembered that in a sample of geriatric patients only $3.7 \%$ were $\mathrm{B}_{12}$ and $1.3 \%$ folate deficient ${ }^{39}$. Nevertheless, those with below median levels of both vitamins had poorer scores on tests of cognitive functioning. The severity of depression was negatively correlated with folate levels, whereas those with an organic psychosis, and a family history of the disorder, had lower $\mathrm{B}_{12}$ levels. Botez et al..$^{40}$ selected a group of 49 depressed patients with low folate levels. After seven to eleven months of folate supplementation the patients were less easily fatigued and distracted, and the scores on all the sub-tests of the Wechsler Intelligence Scale increased, particularly those measuring non-verbal rather than verbal skills.

The elderly as a group have a higher risk of micronutrient deficiency than young adults ${ }^{41}$. Goodwin et al. ${ }^{42}$ correlated biochemical indices of vitamin status and cognitive functioning in the elderly. They reported significant correlations between folate, riboflavin, vitamins $C$ and $B_{12}$ statuses and memory capacity. The levels of riboflavin and folate were also positively related to the ability to think abstractly. Chome et al. ${ }^{43}$ followed up these findings and compared elderly who had a deficiency of at least one vitamin, with those who did not. The deficient group produced poorer scores on tests of mood. However, supplementation failed to alter psychological functioning, although the authors suggested that this may have reflected a small sample size.

Perhaps the most systematic data concerning an association between vitamin status and mood relates to thiamine. When Brozek ${ }^{29}$ supplied a diet, that lacked thiamine, the first signs of deprivation were the development of anorexia, muscular weakness, increased irritability and depression. Responses to the Minnesota Multiphasic Personality Inventory demonstrated a marked deterioration of the psychoneurotic triad of hypochondriasis, depression and hysteria. When thiamine was again administered personality changed rapidly for the better. Subsequently, the association between thiamine status and mood, in those whose normal diet provides a marginal thiamine intake, has been reported in four double-blind placebo controlled studies.

Benton et al. ${ }^{44}$ found a correlation between baseline thiamine status and mood in young healthy females. After four months of taking a multi-vitamin supplement that included thiamine, mood improved when thiamine status improved, and mood was poorer when thiamine status declined. A similar relationship was not found with eight other vitamins. The thiamine status of $18 \%$ of this sample was marginal (transketolase activation 1525\%) and 2\% were deficient (activation greater than $25 \%$ ).

Similarly Smidt et al. ${ }^{45}$ found that the taking of $10 \mathrm{mg}$ of thiamine, for six weeks, was associated with greater feelings of well being, and less fatigue, in a group of elderly Irish females living in the community. The thiamine status in this Irish study was poor; in the case of $48 \%$ of the sample it was deficient and with another $17 \%$ it was marginal. The poor status reflects, in part, the lack of a policy in Ireland of enriching food with thiamine.

In Germany young adult males were screened and a group with a transketolase activation of over $23 \%$ was distinguished who had an adequate level of the other vitamins ( $5 \%$ of the population) $)^{46}$. Poor thiamine status was associated with introversion, inactivity, fatigue, decreased self-confidence and generally poorer mood. Supplementation with thiamine for two months, under a double-blind procedure, resulted in increased sociability and sensitivity. In a British study ${ }^{47} 120$ young adult females took either a placebo or $50 \mathrm{mg}$ of thiamine, each day for two months. An improvement in thiamine status was associated with reports of being more clearheaded, composed and energetic. The taking of thiamine had no influence on memory but reaction times were faster following supplementation. These influences took place in subjects whose thiamine status, according to the traditional criterion, was adequate.

Thus there are four double-blind placebo controlled studies in which thiamine supplementation improved mood in subjects who are not thiamine deficient, as usually defined. The question arises as to whether the response to thiamine was a physiological or pharmacological reaction. Certainly some studies used doses well in excess of the recommended level. There are several reasons to suggest that the improvement in mood reflected a physiological response. Firstly, the improvement in mood in these studies typically correlated with an improvement in thiamine status, that is it was those with an initially poor thiamine status whose mood improved ${ }^{44,47}$. There is consistent evidence 
that a significant minority of industrialized populations consume diets that offer marginal amounts of thiamine ${ }^{48}$. Secondly an improvement in mood has been reported following the taking of a relatively small dose of thiamine $(2 \mathrm{mg})^{46}$.

\section{Iron status}

Iron deficiency is one of the most common nutritional problems in the world, something true in both the developed and developing worlds. In a sample of Spanish women $98.3 \%$ had iron intakes below the recommended dietary levels, 3.9\% had low levels of both haemoglobin and ferritin (iron storage protein) ${ }^{50}$. In Denmark $9.7 \%$ of women had low ferritin levels and $2.2 \%$ iron-deficiency anaemia ${ }^{51}$. In the United Kingdom $51.6 \%$ of females and $11.5 \%$ of males had serum ferritin levels below the accepted cutoff of $20 \mathrm{ng} / \mathrm{l}^{52}$. A low iron status was more common in females, vegetarians and those who were dieting.

The response of many athletes is to take iron supplements, though these should only be consumed when the iron status is low, as excessive supplementation can lead to a low copper and zinc status ${ }^{53}$. However, there seems to be a consensus that low iron status without anaemia is not associated with poorer performance in athletes ${ }^{53}$, although iron deficiency anaemia results in a decreased ability to exercise. Iron deficiency anaemia is associated with reports of poor mood, lethargy and problems of sustaining attention. For example an Australian study reported that anaemic women scored more highly on a questionnaire measuring psychiatric symptoms such as anxiety and depression ${ }^{54}$. A low iron status, without anaemia, has been associated with feelings of depression in those taking the oral contraceptive $e^{52,54}$. The answer to a related question is less certain; does exercise compromise iron status. A recent review did, however, conclude that endurance athletes are at risk of becoming iron deficient ${ }^{55}$. In endurance events, particularly in females, iron status may be compromised because of gastrointestinal bleeding, sweating and damage to red blood cells.

Given the frequency with which low iron status occurs in the general population it is an important nutritional factor that may limit the motivation and capacity to exercise. There can be little doubt that in a minority of the population the lack of energy that results from iron deficiency anaemia will be a serious disincentive to exercise $\mathrm{e}^{53-55}$.

\section{Discussion}

We should expect that what we eat, and the extent to which we exercise, will interact and thus impact on health. However, there has been little attempt to simultaneously consider both factors. It is clear from the example of chocolate ${ }^{13}$ that palatable food can be a source of comfort when we are under stress or experience a poor mood. As there is widespread evidence that the taking of exercise is associated with better mood $^{56}$ it could be predicted that exercise would have an impact on the intake of 'comfort foods' with consequent implications for the overall diet.

In recommending a healthy diet one factor that should be taken into account is how diet makes us feel. Although what we eat is influenced by many factors we are attracted to items that either taste pleasant or improve our mood. We should not overstate the influence and impact of diet on mood, however, there is growing evidence that what we eat has an influence on how we feel.

The findings that diets containing high levels of carbohydrate were associated with better mood ${ }^{3-5}$ are welcome given the health recommendations that we should eat more carbohydrate and less fat.

Benton ${ }^{49}$ marshalled the evidence that very often the first symptoms associated with a sub-clinical intake of a micro-nutrient are usually psychological. There is a series of double-blind placebo controlled studies that report, in at least some of the population, that micronutrient supplementation is associated with better $\operatorname{mood}^{44-47}$ but also memory, attention and scores on intelligence tests.

Some nutritionists argue that if the diet contains sufficient calories and protein then it is probable that the intake of micro-nutrients will be adequate, as they come associated with the rest of the diet. In part such a view may reflect the biological methods that have been used to judge vitamin status. Although nutritionists have not traditionally used psychological measures to monitor nutritional status, it may be argued that they are a particularly appropriate way of examining the possibility that a sub-clinical deficiency exists. Mood and cognitive processing reflect the summated activity of billions of neurones and countless biochemical pathways and their associated enzymes. Thus it may be that relatively small dietary deficiencies, that are dismissed as causing only minor changes to the activity of a single enzyme, will along with a large number of similar minor effects, have a measurable and potentially important cumulative influence on cerebral functioning. It can be argued that if sub-clinical deficiencies exist then psychological functioning, including changes in mood, may be one of the first indications.

There is little evidence that micro-nutrient supplementation improves the performance of athletes. This is not surprising as it is to be expected that the increase in calories associated with intense energy expenditure will result in an increased intake of micro-nutrients. Particular problems may, however, exist in those using exercise as a means of controlling body weight while 
dieting. In the case of both thiamine and iron intake the frequency that a marginal intake occurs gives grounds for concern.

\section{References}

1 Wurtman RJ, Wurtman JJ. Carbohydrates and depression. Sci. Amer. 1989; 260: 50-7.

2 Rosenthal NE, Genhart MJ, Caballero B, Jacobsen FM, Skwerer RG, Coursey RD, Rogers S, Spring BJ. Psychobiological effects of carbohydrate- and protein-rich meals in patients with seasonal affective disorder and normal controls. Biol. Psychiat. 1989; 25: 1029-40.

3 de Castro JM. Macronutrient relationships with meal patterns and mood in spontaneous feeding behavior of humans. Physiol. Behav. 1987; 39: 561-9.

4 Jansen A, van den Hout MA, Griez E. Does bingeing restore bulimics' alleged 5HT deficiency? Behav. Res. Ther. 1989; 27: 555-60.

5 Keith RE, O'Keefe KA, Blessing DL, Wilson DG. Alternations in dietary carbohydrate, protein and fat intake and mood state in trained females cyclists. Med. Sci. Sports Exer. 1991; 23: 212-6.

6 Deijen JB, Heemstra ML, Orlebeke JF. Dietary effects on mood and performance. J. Psychiat. Res. 1989; 23: 275-83.

7 Prusaczk WK, Dishman RK, Cureton KJ. No effect of glycogen depleting exercise and altered diet composition on mood state. Med. Sci. Sports Exer. 1992; 24: 708-13.

8 Wurtman RJ, Hefti F, Melamed E. Precursor control of neurotransmitters. Pharmacol. Rev. 1981; 32: 315-35.

9 Spring B, Chiodo J, Bowen DJ. Carbohydrates tryptophan and behavior: a methodological review. Psychol. Bull. 1987; 102: $234-56$.

10 Lieberman HR, Caballero B, Finer N. The composition of lunch determines afternoon plasma tryptophan ratios in humans. J. Neural Trans. 1986; 65: 211-7.

11 Teff KL, Young SN, Blundell JE. The effect of protein or carbohydrate breakfasts on subsequent plasma amino acid levels satiety and nutrient selection in normal males. Pharmacol. Biochem. Behav. 1989; 34: 829-37.

12 Pijl H, Koppeschaar HPF, Cohen, AF, Iestra JA, Schoemaker HC, Frolich M, Onkenhout W, Meinders A.E. Evidence for brain serotonin-mediated control of carbohydrate consumption in normal weight and obese humans. Int.J. Obes. 1993; 17: $513-20$.

13 Benton D, Greenfield K, Morgan M. The development of the attitudes to chocolate questionnaire. Person. Individ. Diff. 1998; 24: 513-20.

14 Hetherington MM, MacDiarmid JI. Chocolate addiction: a preliminary study of its description and its relationship to problem eating. Appetite 1993; 21: 233-46.

15 Schuman M, Gitlin M.J, Fairbanks L. Sweets chocolate and atypical depressive traits. J. Nerv. Ment. Dis. 1987; 175: 491-5.

16 Hill AJ, Weaver CFL, Blundell JE. Food craving, dietary restraint and mood. Appetite 1991; 17: 187-97.

17 Lester D, Bernard D. Liking for chocolate depression and suicidal preoccupation. Psychol. Rep. 1991; 69: 570.

18 Willner P, Benton D, Brown E, Cheeta S, Davies G, Morgan J, Morgan M. Depression increases craving for sweet rewards in animal and human models of depression and craving. Psychopharmacol. 1998; 136: 272-83.

19 Benton D. Chocolate craving: a biological or psychological phenomenon? In: Knight I, ed. Chocolate and Cocoa: A Review of Health and Nutrition. Oxford: Blackwell Science Limited, 1999: in press.

20 DiTomaso E, Beltramo M, Piomelli D. Brain cannabinoids in chocolate. Nature 1996; 382: 677-8.

21 Rozin P, Levine E, Stoess C. Chocolate craving and liking. Appetite 1991; 17: 199-212.
22 Reid LD. Endogenous opioid peptides and regulation of drinking and feeding. Am.J. Clin. Nutr. 1985; 42: 1099-132.

23 Giraudo SQ, Grace MK, Welch CC, Billington CJ, Levine AS Nalxone's anoretic effect is dependent upon the relative palatability of food. Pharmacol. Biochem. Behav. 1993; 46: 917-21.

24 Spiegel TA, Stunkard AJ, Shrager EE, O'Brien CP, Morrsion MF. Effect of naltrexone on food intake hunger and satiety in obese humans. Physiol. Behav. 1987; 40: 135-41.

25 Wolkowitz OM, Doran MR, Cohen RM, Cohen TN, Wise TN Pickar D. Single-dose naloxone acutely reduced eating in obese humans: Behavioral and biochemical effects. Biol. Psychiat. 1988; 24: 483-7.

26 Trenchard E, Silverstone T. Naloxone reduces the food intake of normal human volunteers. Appetite 1982; 4: 249-57.

27 Yeomans MR, Wright P, Macleod HA, Critchley JA. Effects of nalmefene on feeding in humans. Psychopharmacol. 1990; 100: 426-32.

28 Mandenoff AF, Fumerton M, Apfelbaum M, Margules DL Endogenous opiates and energy balance. Science 1982; 215 1536-7.

29 Brozek, J. Psychological effects of thiamine restriction and deprivation in normal young men. Am.J. Clin. Nutr. 1957; 5: 109-18.

30 Sterner RT, Price RW. Restricted riboflavin: within subject behavioral effects in humans. Am. J. Clin. Nutr. 1973; 26 150-60.

31 Kinsman RH, Hood J. Some behavioral effects of ascorbic acid deficiency. Am. J. Clin. Nutr. 1971; 24: 455-64.

32 Hunter R, Jones M, Jones TG, Matthews DM. Serum B ${ }^{12}$ and folate concentrations in mental patients. Brit. J. Psychiat. 1967; 113: 1291-5.

33 Botez MI, Fontaine F, Botez T, Bachevalier J. Folateresponsive neurological and mental disorders: Report of 16 cases. Eur. Neurol. 1977; 16: 230-46.

34 Carney, MWP, Sheffield MT. Serum folic acid and B12 in 272 psychiatric inpatients. Psychol. Med. 1978; 8: 139-44.

35 Abou-Saleh MT, Coppen C. The biology of folate in depression: implications for nutritional hypotheses of the psychoses. J. Psychiatr. Res. 1986; 20: 91-101.

36 Hector M, Burton JR. What are the psychiatric manifestations of vitamin B12 deficiency? J. Am. Ger. Soc. 1988; 36: 1105-12.

37 Sommer BR, Wolkowitz OM. RBC folic acid levels and cognitive performance in elderly patients: A preliminary report. Biol. Psychiat. 1988; 24: 352-4.

38 Shorvon SD, Carney MWP, Chanarin I, Reynolds H. The neuropsychiatry of megaloblastic anaemia. Br. Med.J. 1980; 281: $1036-8$.

39 Bell IR, Edman JS, Marby DW, Satlin A, Dreier T, Liptzin B, Cole JO. Vitamin B12 and folate status in acute geropsychiatric inpatients: affective and cognitive characteristics of a vitamin nondeficient population. Biol. Psychiat. 1990; 27: $125-37$

40 Botez MI, Botez T, Maag U. The Wechsler subtests in mild organic brain damage associated with folate deficiency. Psychol. Med. 1984; 14: 31-437.

41 Exton-Smith AN, Scott DL, eds. Vitamins in the elderly. Bristol: John Wright and Son, 1968.

42 Goodwin JS, Goodwin J.M, Garry PJ. Association between nutritional status and cognitive functioning in a healthy elderly population. J. Am. Med. Assoc. 1983; 249: 2917-21.

43 Chome J, Paul T, Pudel V, Bleyl H, Heseker H, Huppe R, Kubler, W. Effects of suboptimal vitamin status on behavior. Bibliotheca Nutr. Dieta. 1986; 38: 94-104.

44 Benton D, Haller J, Fordy J. Vitamin supplementation for one year improves mood. Neuropsychobiol. 1995; 32: 98-105.

45 Smidt LJ, Cremin FM, Grivetti LE, Clifford AJ. Influence of thiamin supplementation on the health and general wellbeing of an elderly Irish population with marginal thiamin deficiency. J. Gerontol. 1991; 46: M16-M22. 
46 Heseker H, Kubler W, Westenhofer J, Pudel V. Psychische Veranderungen als Frubzeichen einer suboptimalen Vitaminversorgung Ernabrungs-Umschau 1990; 37: 87-94.

47 Benton D, Griffiths R, Haller J. Thiamine supplementation mood and cognitive functioning. Psychopharmacology 1997; 129: 66-71.

48 Benton D, Haller J, Fordy J. The vitamin status of a sample of young British adults. Int. J. Vit. Nutr. Res. 1997; 67: 34-40.

49 Benton D. Vitamin-mineral supplements and intelligence. Proc. Nutr. Soc. 1992; 51: 295-302.

50 Quintas M, Requejo AM, Ortega RM, Redondo MR, LopezSobaler AM, Gaspar MJ. The female Spanish population: a group at risk of nutritional iron deficiency. Int. J. Food Sci. Nutr. 1997; 48: 271-9.

51 Milman N, Clausen J, Byg KE. Iron status in 268 Danish women aged 18-30 years: influence of menstruation, contraceptive method and iron supplementation. Ann Hematol. 1998; 77: 13-19.

52 Fordy J, Benton D. Does low iron status influence psychological functioning? J. Human Nutr. Dietet. 1994; 7: 127-33.

53 Deakin, V. Iron deficiency in athletes: identification prevention and dietary treatment. In: Burke L, Deakin V. eds. Clinical Sports Nutrition. Sydney, McGraw-Hill. 1994.

54 Rangan AM, Blight GD, Binns CW. Iron status and nonspecific symptoms of female students. J. Amer. Coll. Nutr 1998; 17: 351-5.

55 Nielson P, Nachtigall D. Iron supplementation in athletes. Current recommendations. Sports Med. 1998; 26: 207-16.

56 Thirlaway K, Benton D. Participation in physical activity and cardiovascular fitness have different effects on mental health and mood. J. Psychosom. Res. 1992; 36: 657-65. 